\title{
'Multisensory Holistic Immersion': A Method of Insider Inquiry Skills as a Threshold Concept
}

\section{David Coghlan}

Trinity College Dublin, Ireland

\section{Anne Graham Cagney}

Waterford Institute of Technology, Ireland

\begin{abstract}
Insider inquiry involves being immersed in local situations and generating contextually embedded knowledge which emerges from direct experience. It requires a method that facilitates attending to observable data, envisaging possible explanations of that data and selecting as probable or certain the explanations which provide the best account for the data. This article describes how a method for engaging with insider inquiry in an undergraduate course, that transformed students' thinking and learning beyond their disciplinary boundaries, emerged to be a threshold concept. It seeks to contribute to the field of workplace learning through the exploration of how insider inquiry might be taught as a threshold that is central to the transition from university to working life.
\end{abstract}

Keywords: insider inquiry; threshold concepts; Bernard Lonergan; general empirical method.

\section{Introduction}

Developing an inquiring attentiveness to organisational processes sets up a life skill for workplace learning and is arguably a core skill for undergraduate business students to learn as they move from university into the world of work. In university, students gain many indirect insights into organisations, i.e. through case studies and their reading. In strategy courses, for example, students typically study a case and are conditioned to perceive it in terms of a strategy issue, bringing a priori frameworks, such as competitive analysis, to 
bear on their review of the case. Most courses in our students' experience utilise this approach. Having direct experience of organisations, however, provides access to the reality of organisations with all their paradoxes and problems, and a challenge to adopt a method of inquiry that works from experience rather than from a textbook.

It might be expected that efforts to develop a perspective on inquiring into organisational experience would be difficult and troublesome in educational environments where students are encouraged to analyse organisations from a distance and in terms of a priori categories. Accordingly, such efforts in fact challenge students to think differently, not only about their external environment and but also about themselves. Such challenges may be understood as troublesome knowledge (Perkins, 2006) and may even have the characteristics of a threshold concept (Meyer and Land, 2003; 2006). This paper engages with this challenge and explores how an undergraduate business course was delivered in order to enable students to learn insider inquiry skills. The focus was on students' own direct experience of organisational dynamics, coupled with teaching them a method appropriate to this approach. The settings which students drew on for their direct organisational experience were their part-time, out-of-college jobs. While not the direct focus of this paper, it also feeds into exploration of other workplace settings, such as work placements (Costly and Armsby, 2007; Workman, 2007). The paper is structured as follows. First, the notion of threshold concepts is introduced. Second, insider inquiry is described and a method for engaging in insider inquiry, grounded in the operations of human knowing, is presented. Third, the aims, design and delivery of the course are outlined. Fourth, reflections from teaching the method are explored in the light of threshold concepts. The aim of the paper is to contribute insights on how it emerged that a method for engaging with insider inquiry exhibited the attributes of a threshold concept.

\section{Threshold concepts}

In exploring this challenge, we draw on the notion of threshold concepts (Meyer and Land, 2003; 2006; Coughlan and Graham, 2009; Cousins, 2010). Meyer and Land propose that within each discipline, field or profession there are what they call 'threshold concepts'. Threshold concepts are distinct from what might be described typically as 'core concepts', which are the building blocks that progress understanding of a subject. Core concepts have to be understood but they do not necessarily lead to a different or transformed way of 
viewing the subject matter. Some core concepts are difficult to understand, but not everything that is difficult is a threshold concept. Threshold concepts can be 'considered akin to passing through a portal, or conceptual gateway, thus opening up a new and previously inaccessible way of thinking about something' (Meyer and Land, 2006, p.3). These concepts lead to a transformed way of understanding, or represent how people 'think' in a particular discipline, or how they perceive, apprehend or experience particular phenomena within a discipline. In summary, threshold concepts focus on the difficulty in learning a subject (Cousins, 2010). In the context of this paper, we reflect that it is not just teaching students to learn from experience that is difficult; there is also a theory about why and how it is difficult and threshold concepts provides a perspective on this kind of learning experience.

Threshold concepts usually have five attributes: they are transformative, irreversible, integrative, bounded and troublesome.

- Threshold concepts are transformative in how they reflect the way in which students' perception of themselves and the subject are transformed. When students master a threshold concept, they experience an ontological and epistemological shift that creates a new internal landscape within which new understandings are assimilated into what they know; how they understand things; and sometimes, fundamentally who they are.

- Given their transformative potential, threshold concepts are likely to be irreversible (Davies, 2006). Threshold concepts are difficult to unlearn, which does not imply that they are fixed or that they won't be modified. Students may modify or change their mind about accepting a concept at a later stage but this will happen from a standpoint of understanding it and from making a conscious choice to reject or modify it.

- Threshold concepts are integrative in that they expose 'the previously hidden interrelatedness of something' (Meyer and Land 2006, p.7). The ideas and procedures of a subject make sense and are connected in a way that was not previously understood or perceived.

- Threshold concepts help define how subject areas are bounded, as they clarify the scope of a subject community. 
- Threshold concepts are likely to be troublesome knowledge; tacit and unexamined, they can represent much of the knowledge we rely on every day in our ordinary and professional activities (Perkins, 2006).

Research on threshold concepts has focused largely on concepts within a wide range of disciplines; economics, mathematics, engineering, accountancy and science (Davies and Mangan, 2007; UCL, 2013). What has received much less attention to date is the notion that a learning process may be a threshold concept. We now introduce a learning and reflective process-focused course within which we purport the method emerged to exemplify the attributes of a threshold concept.

\section{Insider inquiry}

'Inquiry from the inside' and 'inquiry from the outside' are two modes of inquiry presented by Evered and Louis (1981). They juxtapose the two approaches. 'Inquiry from the outside' refers to traditional science where the researchers' relationship to the setting is detached and neutral. The basis for validity is argued to be measurement and logic. Typically researchers act as onlookers, and they apply a priori categories to create theoretically universal, context free knowledge.

In contrast, 'inquiry from the inside' involves researchers as actors, immersed in local situations generating contextually embedded knowledge which emerges from direct experience (Brannick and Coghlan, 2007). It is what Goffman (1959) refers to as being 'backstage'. Schon (1995) contrasts how researchers can view practice from the 'high ground', where they can study issues from a distance, for example, because they are not organisational members or because their data are based on pre-constructed surveys or interviews. Or they can be immersed in the 'swampy lowlands' where problems are messy, confusing and incapable of a technical solution, because they are either organisational members whose actions influence the reality they see, or are outsiders who are contracted to influence what they see. For attentive students, attention to what goes on around them can evoke questions about how organisations function and set the foundations for learning. Experience and inquiry as from the perspective of being insiders can create the potential of developing skills that students can draw on in their future careers, especially those who become managers in later life. 
Insider inquiry begins and works from direct personal experience. Evered and Louis (1981, p.387) refer to their method of insider inquiry as 'multisensory holistic immersion' and as 'messy, iterative groping' which they contrast with procedures of forming and testing explicit hypotheses associated with the scientific method. As insiders listen to what people say, observe what people do and question the outcomes of both deliberate and spontaneous action, intended and unintended, they learn to 'decipher the blooming, buzzing confusion' around them (Evered and Louis, 1981, p.386). Without a prescribed set of formulae and frameworks that can be applied in a uniform and predictable manner, students struggle to learn the method. It requires a different kind of learning.

No matter which way one approaches it, undergraduate students may find insider inquiry difficult and troublesome for several reasons. One reason is that their academic learning prior to this will tend to have been primarily propositional rather than practical. They will have studied theories, concepts and frameworks and applied them to paper-based cases, which typically tend to be constructed on a single discipline basis. Engaging with how these theories are enacted in practice involves an ability to integrate fields of study, which hitherto in the students' experience may not have been integrated.

Moreover, learning from the closeness of direct experience where meanings are socially constructed, requires students to be skilled both in understanding what is taking place in the environment around them and in grasping their own meaning-making processes (Campbell, 2000). This is learning that starts with students' experience and is different in that, unlike a case study that is finite and fixed, students have to conduct the application and analysis of the appropriateness of frameworks within that live and messy situation in which they find themselves. In addition, students are challenged to reflect upon and learn about their own learning processes, in other words, the meta-cognitive moment that is occurring within a dynamic and fluid situation. Accordingly, it is paramount to have a method which students can learn and that enables them to practice this 'multisensory holistic immersion' and 'messy iterative groping' within course constraints. This leads us to introduce and to discuss an empirical method that is appropriate to insider inquiry. 


\section{A general empirical method for insider inquiry}

What differentiates us humans from other forms of living organisms is our ability to be selfaware. This self-awareness is central to learning and to learning-in-action because it means that we can be aware of our experience, ask questions about it, come to judgements, make decisions and take action (Dewey, 2007). The philosopher-theologian Bernard Lonergan describes the structure of human knowing as a three-step process: experience, understanding and judgement (Lonergan, 1992; Flanagan, 1997; King, 2011) (see Table 1). First, we attend to our concrete experience. Then we ask questions about our experience and receive an insight (understanding) and we follow that up by reflecting and weighing up the evidence to determine whether our insight is correct or not (judgement). Experience is the empirical level of consciousness and is an interaction of inner and outer events. Not only can we see, hear, smell, taste and touch, imagine, remember, feel, and think, but we can also experience ourselves as seeing, hearing, thinking, feeling, remembering and imagining. Sensory data are what we experience but do not yet understand. So we ask questions, 'what does this mean?'. Answers to such questions come in the form of insights, which are creative acts of understanding, of grasping and formulating patterns, unities, relationships and explanations, in response to questions posed to our experience.

\begin{tabular}{|l|l|}
\hline Experience & $\begin{array}{l}\text { Seeing, hearing, smelling, } \\
\text { tasting, touching, } \\
\text { remembering, imagining, } \\
\text { feeling... }\end{array}$ \\
\hline Understanding & $\begin{array}{l}\text { Inquiring, understanding, } \\
\text { formulating what is being } \\
\text { understood }\end{array}$ \\
\hline Judgment & $\begin{array}{l}\text { Marshaling evidence, } \\
\text { testing, judging }\end{array}$ \\
\hline Decision/Action & $\begin{array}{l}\text { Deliberating, valuing, } \\
\text { deciding, choosing, taking } \\
\text { action, behaving... }\end{array}$ \\
\hline
\end{tabular}

Table 1. The Operations of Human Knowing and Doing

Insights are common; we get thousands of them every day. They are not always accurate or true. The question then is, does the insight fit the evidence? This opens up a question for reflection. Is it so? Yes or no? Maybe? We don't know. The shift in attention turns to an inquiry for accuracy, sureness and certainty of understanding. So we move to a new level of the cognitional process, where we marshal and weigh evidence and assess its sufficiency. We set the judgement up conditionally - if the conditions have been fulfilled, 
then it must be true or accurate. There may be conflicting judgements and we may have to weigh the evidence and choose between them. Through judgement we can use terms like accurate, correct and true. We need to distinguish judgements of fact and judgements of value. A judgement of fact affirms that something is true/not true, or is correct/not correct. A judgement of value affirms that something is $\mathrm{good} / \mathrm{bad}$, important/unimportant and so on.

Lonergan (1992) argues that human knowing is not any of these operations on their own. For him, all knowing involves experience, understanding and judgement. He acknowledges that we are not always attentive to experience, that understanding may not spontaneously flow from experience, that many insights may be wrong, that interpretations of data may be superficial, inaccurate, biased and that judgements may be flawed. He refers to these as flights from understanding and oversights. He argues that we can gain insight into these negative manifestations of knowing by the same three-fold process of knowing. The pattern of the three operations is invariant in that it applies to all settings of cognitional activity, whether solving a crossword clue, solving an everyday problem or engaging in scientific research. To reject or dismiss this pattern involves experience, understanding and judgement and, paradoxically, confirms it.

We have provided a detailed account of the operations of human knowing, which while invariant and recognisable in human experience, nevertheless are difficult to identify and distinguish in concrete situations. Later in this article we will discuss the theoretical frameworks that were taught which provided constructs to help frame insights from their concrete experiences. What is central to the dynamic of the course under exploration here is the emphasis on the learning process of the students. Lonergan's work in this regard is valuable as he adopts a personal approach to grasping the operations of knowing, which he calls self-appropriation. Appropriating our intellectual activities means to become aware of them, be able to identify and distinguish them, to grasp how they are related, and to be able to make the process explicit. Accordingly, we not only experience, understand and judge the world around us but we experience, understand and judge our own process of knowing and learning. The cognitional operations of experience, understanding and judgement form a general empirical method, which requires: 
- Attention to observable data.

- Envisaging possible explanations of those data.

- Preferring as probable or certain the explanations which provide the best account for the data (see Table 2).

\begin{tabular}{|c|c|c|}
\hline Be attentive & to data of sense \& consciousness & \\
\hline Be intelligent & Envisaging possible explanations of that data & \\
\hline Be reasonable & $\begin{array}{c}\text { Preferring as probable or certain the explanations } \\
\text { which provide the best account for the data }\end{array}$ & for action \\
\hline Be responsible & & \\
\hline
\end{tabular}

Table 2 The General Empirical Method

Appropriation of our own knowing process does not happen in one single leap; it is a slow painstaking developmental process that is founded on our attention to the operations of knowing in the unfolding of our own experience. Although his ideas are not necessarily new, Lonergan's method possesses clarity of thought and provides us with tools that enable us to get a firm grasp on the process of learning that students can exploit in their 'multisensory holistic immersion' as insiders in their particular organisational settings.

\section{Critical thinking}

The general empirical method provides a method for engaging in critical thinking (King, 2011). It challenges learners to pose questions to themselves, not only about what is going on around them, but also how they are framing their interpretations. In other words, the general empirical method works with both data of sense and data of consciousness and does not treat external situations without taking into account the corresponding operations of the person, and does not treat a person's cognitive operations without taking account of the corresponding specific situation in which a person finds themselves and the questions that arise from being in these settings. Moon (2008, p.126) argues that the notion of judgement is central to critical thinking, whereby a person can make an effective provision of evidence to justify a reasonable judgement: 'Critical thinking can be seen as a form of learning, in that new knowledge, in the form of judgement, is formed in the process'. In this 
regard, the general empirical method has close affinities to evidence-based practice (Rousseau, 2006).

Insider inquiry of its nature requires a method that accommodates direct experience, closeness, and a framework to work with the 'blooming, buzzing confusion' in the swampy lowlands. Accordingly, Lonergan's articulation of the cognitive structure acted as an empirical method for the course participants challenging them to perform the operations of attentiveness, intelligence and reasonableness.

\section{The 'Exploring Organisational Experiences' course}

The 'Exploring Organisational Experiences' course (15 ECTS, equivalent to 30 UK credits) was a final-year option for students who were within months of graduation, and who had studied a broad range of business and organisational subjects over their four year programme. The learning outcomes were framed that participants would:

1. Learn how to inquire critically into organisational dynamics from the perspective of being an insider-participant.

2. Have practised a general empirical method that would enable them to learn critical thinking skills.

3. Have constructs for reflecting on organisational dynamics.

The course outline stated that the core ingredient of the course was to be curiosity and inquiry into organisational processes which would be supported by conceptual frameworks aimed to guide students' understanding. They would be required to show how they would learn to observe and inquire into organisational processes, drawing on their direct experience and insider familiarity from part-time jobs, summer jobs, family business, voluntary work and participation in university student societies.

The content of the course was grounded in Coghlan and Rashford's (2006) book which discusses organisational issues such as interlevel dynamics, change and strategy, and which works from a reflective approach. Evered and Louis' (1981) seminal article was circulated and discussed and supplemented with material from Goffman's (1959) notion of front- and back-staging. In the first semester, lectures were given on the individual, team, 
interdepartmental group and organisational levels respectively, and interlevel dynamics (how each level affects and is affected by each of the others). In the second semester, broad themes in the processes of organisation development and strategy were introduced and reviewed in terms of interlevel dynamics. While these frameworks were introduced in the course, it was expected that students would draw also on relevant frameworks from other courses. In doing so they would have to demonstrate how the use of any particular framework was relevant in articulating an insight from an experience and be able to verify how that insight was confirmed.

The somewhat subversive aim of the course was to transform students' ways of learning from the traditional didactic model that works from the textbook to cases, to engaging in a process of reflection on experience. As it was a final year course and sought to facilitate the transition from class-room learning of university life to work-based learning in organisations, the image of a portal or a threshold applies to both the students' stage of life stage transition, and to the transformation of their way of learning and making sense of their experiences.

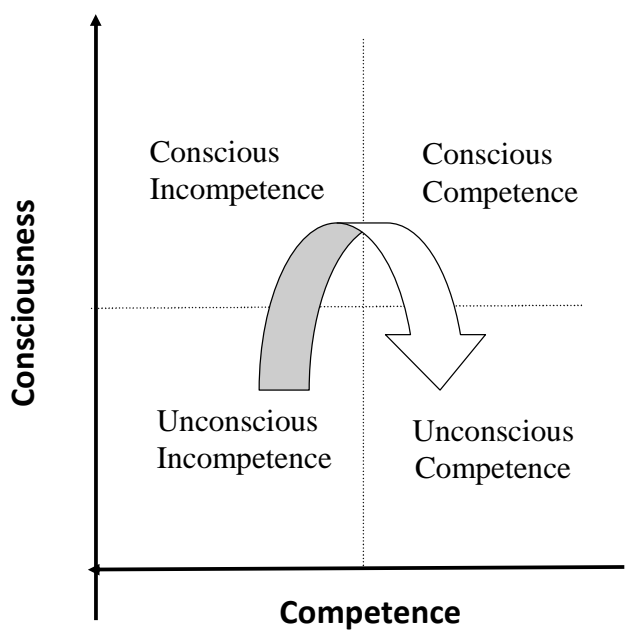

Figure 1

The Process of Learning to Appropriate the General Empirical Method

Figure 1 outlines the process of learning to appropriate the general empirical method. Quadrant 1, unconscious incompetence, captures the place in which students do not know that they do not know that they do not have critical thinking skills. As they engage in the course they realise that they do not have these skills and become conscious of their incompetence and make the commitment associated with deep learning to engage with the concepts and the method and the required learning process, thereby moving to 
Quadrant 2. They practice the skills of insider inquiry and the general empirical method both within their chosen organisations and through the reflection required by the course assignments and gradually mastering both content and process. The intention was that by the end of the course they have learned some skills in applying them consciously, and the overall goal is that as they move through life they internalise them, consolidate the learning, and continue to enhance these skills to become in effect reflective practitioners (Quadrant 4).

We are arguing that engaging with insider inquiry is difficult because it requires the students to expand their ways of thinking and practicing beyond their chosen disciplinary boundaries (Donald, 2002). Furthermore, the nature of this difficulty is compounded because the method of inquiry from the inside is drawn from a different discipline i.e. philosophy. Therefore, commitment to insider inquiry becomes a commitment to the method. It was anticipated that students would experience learning anxiety, as their learned competence of how to write assignments, complete courses and get good grades, would not necessarily apply. Additionally, the students' 'taken-for-granted' nature of their own experienced ways of learning would be challenged. The hope was that in the process students would understand what is taking place in their chosen organisational settings and grasp their own meaning making processes. Accordingly, there was an initial focus on attending to cognitional processes in order to unfreeze assumptions by disconfirming traditional expectations of what learning on this course would involve (Schein, 1996).

\section{The structure of the course}

The course was structured around a weekly lecture for all the participants and a weekly seminar conducted in two separate sessions to facilitate smaller numbers and deeper discussion. Course assessment consisted of two major papers (4000 words), three short hand-in assignments (a two-page pensee), keeping a reflective journal, and a three-hour final examination. The two major papers were due at the end of first semester and at the end of the course respectively. The three pensees were scheduled after each theory block and they invited students, using the general empirical method, to reflect on the questions that the theory block was evoking in them about their case (Table 3). Students were required to keep a reflective journal in which they explored their experiences, insights and judgements of events in their chosen organisations, in other courses, and in their lives. 
These were inspected on several occasions during the course. At intervals throughout the course, classes were devoted to engaging in the general empirical method through, for example, a series of arithmetic puzzles and crossword clues. These exercises reinforced students' awareness of the distinctive cognitive operations of experience, understanding and judgement, so that they would gain confidence in using the method. This learning in respect of the method was further enhanced by a formal and informal formative structure of providing both written and face-to-face feedback and support to each student on receipt of the pensees and the essays.

Table 3. Questions for reflection.

\begin{tabular}{|l|l|}
\hline \multicolumn{1}{|c|}{ Pensee } & \multicolumn{1}{c|}{ Question } \\
\hline Pensee 1 & $\begin{array}{l}\text { From the experience as an insider of your case } \\
\text { organization what insights are emerging about } \\
\text { relationship between the individual and the } \\
\text { organization? }\end{array}$ \\
\hline Pensee 2 & $\begin{array}{l}\text { From the experience as an insider of your case } \\
\text { organization what insights are emerging about how the } \\
\text { change is managed? }\end{array}$ \\
\hline Pensee 3 & $\begin{array}{l}\text { From the experience as an insider of your case } \\
\text { organization what insights are emerging about how the } \\
\text { strategic process operates? }\end{array}$ \\
\hline
\end{tabular}

Over several years of this course, the work of the students has covered a wide range of organisational settings. Examples included a small supermarket moving to a new premises, a major re-orientation to customer service by an international renowned retail chain, the restructuring of a law firm, a move to an electronic order system by a family trucking firm, the rescue of a student university society which was in danger of losing its corporate sponsorship, and several accounts of experiences in fashion boutiques.

\section{The general empirical method of insider inquiry as a threshold concept}

The focus of the course was on the process of learning to attend to insider inquiry and on developing the skill of employing the general empirical method, rather than on any 
particular organisational issues that students may have discussed. The structure of human knowing acted as an empirical method for the course participants and was integral to enabling the students to engage in insider inquiry. Our experience is that the students on the course struggled with what was a reversal of their well-embedded learning process and thereby struggled with learning to think differently. Our insight is that the course required double-loop learning on the part of the students; double loop learning involves changing the frame by which questions are asked (Argyris, 1982). Students were challenged to create a new mental model for themselves for how they would engage in and learn in the course and achieve good grades. Attending to cognitional processes is difficult for undergraduate students to grasp. While not everything that is difficult to learn is a threshold concept, attending to the method of inquiry from the inside meets most of the characteristics of a threshold concept.

As Meyer and Land (2006) discuss, engagement with a threshold concept involves liminality, that is, being in an unstable space of not-knowing, where students oscillate between old and emergent understanding in a transition state. Additionally, the impact of engagement with the concept involves disjuncture, described by Jarvis (2006) as a tension that develops between the self and our world view creating a sensation of lack of 'fit' between the situation in which one finds oneself and one's world view. Jarvis (2006, p.16) describes this as 'the point when our biographical repertoire is no longer sufficient to cope with our situation, causing our unthinking harmony to be disturbed leaving us with a feeling of unease'. The experience of learning during disjuncture is discussed by Meyer and Land (2006) and described as being in an unstable space of knowing/not knowing, of oscillating between old and emergent understandings. A sense of psychological safety was created through a supportive teaching-learning environment based on small group seminars, where personal experiences and learning were shared (Graham and Coghlan, 2009). 


\begin{tabular}{|c|c|c|}
\hline $\begin{array}{l}\text { Attributes of } \\
\text { Threshold } \\
\text { Concepts }\end{array}$ & Insider Inquiry & General Empirical Method \\
\hline Transformative & $\begin{array}{l}\text { Learning to attend to experience and to stand } \\
\text { back from it by questioning, both the outer } \\
\text { experience of what took place and the inner } \\
\text { experience of how one constructs } \\
\text { interpretations. }\end{array}$ & $\begin{array}{l}\text { Using the general empirical method defined in terms of } \\
\text { attending to own cognitional operations changes student's } \\
\text { perception of themselves and the subject area. }\end{array}$ \\
\hline Irreversible & $\begin{array}{l}\text { Learning to stand back from what one is close } \\
\text { to is irreversible. Difficult to asses in short } \\
\text { term for students }\end{array}$ & $\begin{array}{l}\text { Developing a critical thinking stance on life, where } \\
\text { experience is subjected to inquiry, insight, testing and } \\
\text { judgement is an irreversible process. Difficult to asses in } \\
\text { short term for students }\end{array}$ \\
\hline Integrative & $\begin{array}{l}\text { As life does not deliver in terms of neatly } \\
\text { packaged disciplinary insider inquiry integrates } \\
\text { academic disciplinary fields through } \\
\text { experience }\end{array}$ & $\begin{array}{l}\text { Working from a general empirical method performs an } \\
\text { integrative function as it crosses all areas of human } \\
\text { activity and can be used in scientific inquiry and in every } \\
\text { dar living. }\end{array}$ \\
\hline Bounded & Process as boundedness requires futher wor & $\begin{array}{l}\text { Insight into boundedness of thinking within } \\
\text { mizational disciplines and functions. }\end{array}$ \\
\hline Troublesome & $\begin{array}{l}\text { As a reversal of well-embedded learning } \\
\text { process, beginning from 'multisensory holis } \\
\text { immersion' and learning to engage in 'messy } \\
\text { iterative groping' is troublesome. }\end{array}$ & $\begin{array}{l}\text { jugnitional process is something we take for granted. We } \\
\text { troublesome because it is taken for granted and rarely is } \\
\text { magexplicit. }\end{array}$ \\
\hline
\end{tabular}

Table 4 Insider Inquiry and the General Empirical Method as Threshold Concepts

The insight that emerged for us is that the method for engaging with insider inquiry exhibits the attributes of a threshold concept (Table 4). Both insider inquiry and using the general empirical method, defined in terms of attending to their own cognitional operations, changes students' perception of themselves and the subject area. Learning to attend to experience and to attend to how to move from experience, through understanding to judgement, is transformative in that they learn how to assess the value of expert statements and to know when to accept opinions and when to doubt. Learning to attend to experience and to stand back from it by questioning, involves both the outer experience of what took place and the inner experience of how one constructs interpretations.

Irreversibility is difficult to affirm as students were still in the educational system and so the potential to revert to learned patterns of thinking remained, particularly at examination time when they are embedded in that pattern for other examinations. However, it may be noted that a former course participant has returned several times to speak to the class and has spontaneously narrated how he is using the general empirical method in his current role as a financial auditor. 
Threshold concepts are integrative in that they expose 'the previously hidden interrelatedness of something' (Meyer and Land, 2006, p.7). The ideas and procedures of a subject make sense and are connected in a way that was not previously understood or perceived. As life does not deliver experience in terms of neatly packaged disciplinary concepts, insider inquiry provides the opportunity to integrate academic disciplinary fields through experience. Working from a general empirical method performs an integrative function as it crosses all areas of human activity and can be used in scientific inquiry and in everyday living. As insider inquiry crosses the boundaries of discrete disciplines and the work on threshold concepts to date has focused on content concepts rather than process, the boundedness of the empirical method in insider inquiry remains open for discussion.

Finally, as a reversal of learning processes in which students have been socialised all their educational lives, the shift to 'multisensory holistic immersion' and learning how to engage in 'messy iterative groping' is troublesome. Cognitional process is something we take for granted. We just do it. Therefore, attending to cognitional processes is also troublesome because it is taken for granted and rarely made explicit.

\section{Conclusions}

In this paper we explore how for undergraduate business students, insider inquiry skills, engaged in through a general empirical method, act as a threshold concept. The foundation of this course is that insider inquiry is an important area of learning for students who are in transition from university life to the world of working in organisations. In Evered and Louis's (1981)terms such inquiry is engaged by 'multisensory holistic immersion' and 'messy, iterative groping' in what Schon (1995) termed the 'swampy lowlands'. The insider inquiry approach contrasts with the outsider observer approach of the case study method. Engaging in insider inquiry demands a reversal of academic learning approaches, whereby the students begin with an informed engagement with experience rather than an engagement solely with theory. Learning from the closeness of direct experience, where meanings are socially constructed, requires students to be skilled in both understanding what is taking place in the environment around them and in grasping their own meaningmaking processes. This is learning that is not amenable to frameworks and simple rules, but rather by direct engagement. 
Learning to bring an attitude of inquiry to experience is at the heart of the educational process and we sought to make this explicit in this course development with our business students. As we experience processes in organisations, we see things happening and we hear what is said - and we wanted our students to consider: how do we understand them?; and then what judgements do we make about them? We wanted our students to realise that we need to learn to be attentive to what is happening, ask to ask ourselves relevant questions, questions that are based on wanting to understand what is going on. We encouraged students to try to keep an open mind as to what events might mean until they had gathered evidence and verified it by judgement. Learning to develop an inquiring attentiveness to organisational processes which occur around them is a core skill for business students to learn. We wanted our students to realise that they can learn to observe themselves being an observer and learn to understand themselves as questioners. While our hope is that long after they have left university and have forgotten the multiplicity of specific theories they learned during the course of the studies, they will have internalised the general empirical method, this is not assured. When students explored experiences in their home and social life in their journals, as some did, they demonstrated an internalisation. Nevertheless, because learning a method of attending to cognitional processes, a method that is grounded not in any thesis or grand theory but in the recognisable operations of human inquiry, is accessible, this hope is not unrealisable, especially for those who crossed the learning threshold.

The threshold concept itself is an emerging construct that is contributing significantly to understanding the learning process. It provides a framework for engaging with concepts that are transformative, irreversible, integrative, bounded and troublesome. This paper has described how a method for engaging with insider inquiry in a course which transformed students' thinking and learning beyond their disciplinary boundaries emerged to be a threshold concept. During the delivery of a course, students developed their metaawareness using the theories and concepts of their subject but within a messy life situation rather than a finite and safe (case study) one. It has sought to contribute to the field of workplace learning through the exploration how insider inquiry might be taught, a threshold that is central to the transition from university to working life. It also seeks to contribute to the literature on threshold concepts and to the application of Lonergan's (1992) method to a hitherto unexplored context. 


\section{References}

Argyris, C. (1982) Reasoning, learning and action. San Francisco: Jossey-Bass.

Brannick, T. and Coghlan, D. (2007) 'In defense of being 'native': the case for insider academic research', Organizational Research Methods, 10(1), pp. 59-74.

Campbell, D. (2000) The social construction of organizations. London: Karnac.

Coghlan, D. and Brannick, T. (2010) Doing action research in your own organization. $3^{\text {rd }}$ edn. London: Sage.

Coghlan, D. and Rashford N.S. (2006) Organization change and strategy. An interlevel dynamics approach. Abingdon: Routledge.

Costly, C. and Armsby, P. (2007) 'Methodologies for undergraduates doing practitioner investigations at work', Journal of Workplace Learning, 19(3), pp. 131-145.

Coughlan, P. and Graham, A. (2009) 'Embedding a threshold concept in teaching and learning of product development management', Creativity and Innovation Management, 18(3), pp. 190-198.

Cousins, G. (2010) 'Neither student-centred nor teacher-centred: threshold concept and research partnerships', Journal of Learning Development in Higher Education, Issue 2, February, pp. 1-9.

Davies, P. (2006) 'Threshold concepts: how can we recognize them?', in Meyer, J. and Land, R. (eds.) Overcoming barriers to student understanding: threshold concepts and troublesome knowledge. Abingdon: Routledge, pp. 70-84.

Davies, P. and Mangan, J. (2007) 'Threshold concepts and the integration of understanding in economics', Studies in Higher Education, 32(6), pp. 711-726.

Dewey, J. (2007) How we think. Stilwell, KS: Digiread.com Publishing. 
Donald, J.G. (2002) Learning to think: disciplinary perspectives. San Francisco: JosseyBass.

Evered, R. and Louis, M.R. (1981) 'Alternative perspectives in the organizational sciences: 'Inquiry from the inside' and 'inquiry from the outside", Academy of Management Review, 6(3), pp. 385-395.

Flanagan, J. (1997) Quest for self-knowledge. Toronto: Toronto University Press.

Goffman, E. (1959) The presentation of self in everyday life. New York: Doubleday.

Graham, A. and Coghlan, D. (2009) 'Creating the learning space for insider inquiry: threshold concepts in observing organisations', in Rust, C. (ed.) Improving student learning through the curriculum. Proceedings of the 16th international symposium improving student learning. University of Durham, Durham 1-3 September 2008. Oxford: Oxford Brookes University, pp. 221-232.

Jarvis, P. (2006) Towards a comprehensive understanding of human learning. Abingdon: Routledge.

King C.B. (2011) Finding the mind: pedagogy for verifying cognitional theory. Lanham, MD: University Press of America.

Lonergan, B.J. (1992) 'Insight: an essay in human understanding', in Crowe, F. and Doran, R. (eds.) The collected works of Bernard Lonergan, Vol. 3. Toronto: University of Toronto Press. (original publication, London: Longmans, 1957)

Meyer, J. and Land, R. (2003) 'Threshold concepts and troublesome knowledge (1): linkages to ways of thinking and practising within the disciplines', in Rust, C. (ed.) Improving student learning - ten years on. Oxford: OCSLD, pp. 412-424.

Meyer, J. and Land, R. (2006) Overcoming barriers to student understanding: threshold concepts and troublesome knowledge. Abingdon: Routledge.

Moon, J. (2008) Critical thinking: an exploration for theory and practice. Abingdon: Routledge. 
Perkins, D. (2006) 'Constructivism and troublesome knowledge', in Meyer, J. and Land, R. (eds.) Overcoming barriers to student understanding: threshold concepts and troublesome knowledge. Abingdon: Routledge, pp. 33-47.

Rousseau, D.M. (2006) 'Is there such a thing as 'evidence-based management?" Academy of Management Review, 31(2), pp. 256-269.

Schein, E.H. (1996) 'Kurt Lewin's change theory in the field and in the classroom: notes toward a model of managed learning', Systems Practice, 9(1), pp. 27-47.

Schon, D.A. (1995) 'Knowing-in-action: the new scholarship requires a new epistemology', Change, November/December, pp. 27-34.

UCL (2013) Threshold concepts: undergraduate teaching, postgraduate training and professional development - a short Introduction and bibliography. Available at: http://www.ee.ucl.ac.uk/ mflanaga/thresholds.html (Accessed: 22 February 2013).

Workman, B. (2007) 'Casing the joint': explorations by insider-researcher preparing for work-based projects', Journal of Workplace Learning, 19,(3), pp. 146-160.

\section{Author details}

Anne Graham Cagney is a Lecturer in the School of Lifelong Learning \& Education, at Waterford Institute of Technology. Her research interests are in enhancing teachinglearning environments particularly in professional development programmes in higher education. She is currently exploring the links between useable knowledge, transformative learning, and organisational development that support educational, business and organisational success. Anne is Research Fellow, Business School, Trinity College Dublin and HETL (International Higher Education Teaching and Learning Association) liaison for Ireland.

David Coghlan is Professor of Organization Development at the School of Business, Trinity College Dublin, Ireland and is a Fellow of the College. He is author of eight 
books, including Doing Action Research in Your Own Organization (3rd. Sage, 2010) and over seventy articles and book chapters. 